\title{
TIME TO GET SERIOUS: TRAINING GRADUATE STUDENTS IN TEACHING
}

\author{
Catherine J. Denial
}

Knox College

In late August, 1994, I walked into a classroom in the basement of Holton Hall on the University of WisconsinMilwaukee's campus and began my career as a college-level instructor of history. I had a stack of books in my arms to project a façade of expertise and had dressed up for the occasion. Since I was flatly terrified of teaching, I had wondered to myself who might do a stellar job in front of a class full of American undergraduates. I landed upon the character of Dana Scully from the X-Files, and-in my own head-pretended to be her for the entire duration of class.

I was, as the title of Jonathan Zimmerman's book suggests, an amateur. Responsible for six discussion sections per week, containing twenty students apiece, I had received one week of training on how to teach, exactly none of which I remember now. My memories of that first semester of teaching are mostly of the truly daunting stack of blue books I had to grade at midterm, and how everyone failed on my first pass because I didn't understand that points were a stand-in for certain letter grades, and not something you docked one-by-one.

UWM was not especially bad at teaching people to be teachers-it's simply that, as Zimmerman suggests, the department was set up to create researchers. It did that job well. I learned a historian's craft in my Master's program at that institution, my skill set improving by leaps and bounds over what it had been as an undergrad. In this, I was like many thousands of other brand-new graduate students in the fall of 1994. I was on the road to becoming a thoughtful, careful scholar, but I was teaching because it was what you did along the way.

Too many graduate students still weather this experience. While there have, as Zimmerman notes, been improvements in the way that incipient and ongoing instructors are taught to think about their teaching, it is still not a primary focus of history graduate education, even as graduate students are on the front lines of teaching at almost every institution. Teaching is assumed to be something a person can intuit, or perhaps do because they have learned from model teachers themselves. But as Zimmerman points out, this problem has been around for more than a century. We cannot reflexively look to senior academics to learn how to teach; they lacked models, too.

Teaching is a profession; it is the subject of serious inquiry and scholarly research; it defines the experience of every undergraduate at every institution of higher learning in the country; and it deserves respect. That respect must translate into serious pedagogical instruction in history graduate programs. Graduate students are educators, and deserve to know about the rich scholarship of teaching and learning that is available to them. They deserve professional development that equips them to be insightful, active, reflective, and compassionate instructors; they deserve targeted disciplinary support beyond what centers of teaching and learning (all hail!) provide. While many graduate students seek out opportunities to learn about teaching themselves, this should not be an extra burden they shoulder, but rather a standard provision of the programs we build.

Not all graduate students will become professors, not least of all because of the profound inequalities in our current education systems and the whittling away of tenure-track lines. But all graduate students are, I think, likely to be life-long educators, no matter what career path they take. Learning to express complex ideas in accessible language, to facilitate growth, to think about the neurology and psychology of how we learn and retain new ideas, to inject fun into intellectual labor, to lead-these are truly transferable skills.

Graduate students should expect to be championed and valued as the standard bearers of historical learning. We should all feel equipped to teach confidently, as secure in our abilities in the classroom as in our work in the archives. As historians, we need to do better by one another, and commit to the principle of transforming new instructors into well trained, supported, and appreciated professionals. To do any less is to abdicate responsibility for the lifeblood of history education. 